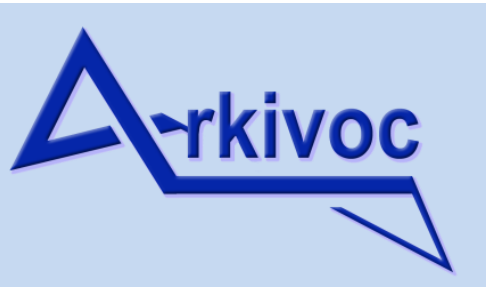

Free to Authors and Readers
A Platinum Open Access Journal for Organic Chemistry

DOAJ Seal
Review

Arkivoc 2021, part ii, 99-117

\title{
Amino acids with fluorinated olefinic motifs - synthetic approaches
}

\author{
Katarzyna Salamon-Krokosz, Katarzyna Koroniak-Szejn, ${ }^{*}$ and Henryk Koroniak
}

Faculty of Chemistry, Adam Mickiewicz University

ul. Uniwersytetu Poznańskiego 8, 60-614 Poznań, Poland

Email: katarzyna.koroniak@amu.edu.pl

\section{In dedication to Professor Zbigniew Czarnocki on the occasion of his $66^{\text {th }}$ anniversary}

Received 09-15-2020

Accepted Manuscript 11-11-2020

Published on line 11-22-2020

\begin{abstract}
Peptidomimetics are molecules related to natural peptides that have an artificial unit incorporated in their structure. Such structural modifications, mimicking properties of natural amino acids, can be responsible for differently pronounced activity. Among others, amino acid derivatives with fluorinated olefinic motifies can act as building blocks in the synthesis of complex molecules with potential biological activity. Therefore, the synthetic approaches to the fluorinated olefinic moiety amino acids are of interest to organic chemists. There are different synthetic methods yielding fluorinated olefins having significant value in the synthesis of amino acid derivatives. This mini review describes the latest achievements in the synthesis of amino acids bearing mono-, di- or trifluorovinyl moiety.
\end{abstract}

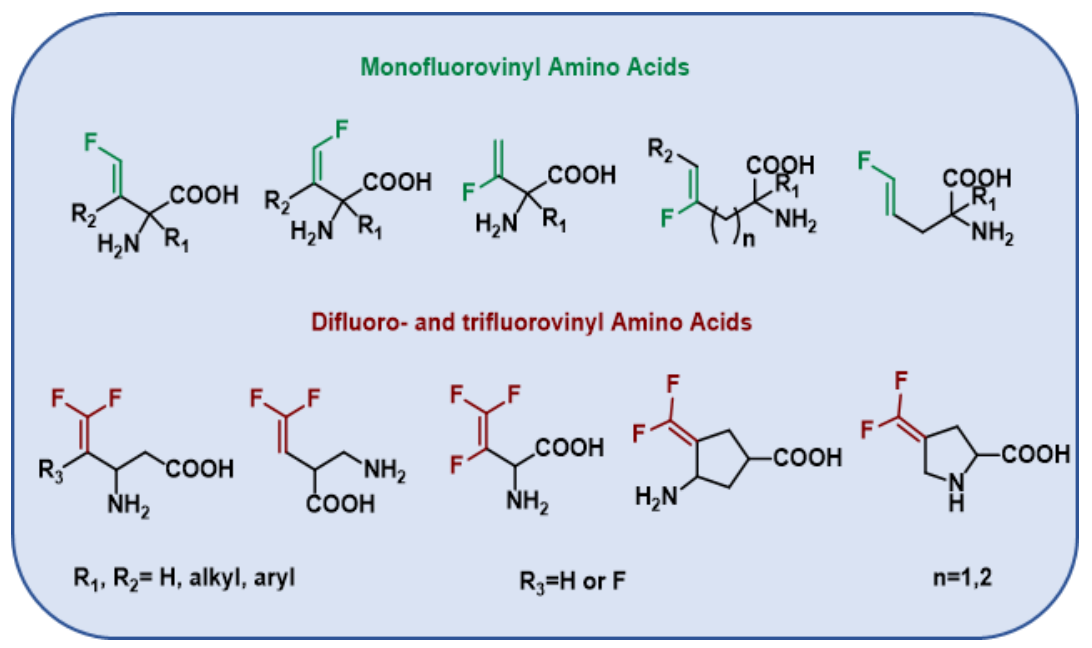

Keywords: Monofluorovinyl moiety, difluorovinyl moiety, trifluorovinyl moiety, amino acids, peptidomimetics, biological activity 


\section{Table of Contents}

1. Introduction

2. Monofluoroolefinic Amino Acid Derivatives

3. Di- and Trifluoroolefinic Amino Acid Derivatives

4. Conclusions

List of Abbreviations

References

\section{Introduction}

The incorporation of fluorine to an organic molecule often induces remarkable changes in their biophysical properties including solubility, lipophilicity, conformational and metabolic stability as well as chemical reactivity. ${ }^{1,2}$ The changes in reactivity have far-reaching consequences. Incorporation of fluorine often affects a molecules bond energy, acidity and basicity, ability to form hydrogen bonds and its geometry. ${ }^{3-6}$ Therefore, the incorporation of fluorine or fluoroalkyl moieties into molecules is broadly used in the synthesis of drugs and biologically active compounds. 7,8 This is one of the reasons why fluorination methods are widely studied in synthetic organic chemistry.

Fluorinated amino acids as well as fluorinated peptides have been widely studied and used in the design and synthesis of novel pharmaceuticals. They are very useful building blocks with regards to the synthesis of bioactive compounds. The big interest in the synthesis of fluorinated amino acids and peptides is also notable in the literature. Recently, in 2019 Professor Koksch published a broad review about the synthetic methods of fluorinated amino acids. ${ }^{9}$ Additionally, synthetic approaches were also discussed earlier by the Koksch group in 2008. ${ }^{10}$ Since the synthetic approaches to amino acids having fluorinated olefinic fragments were not well covered, we present herein, a short overview of the synthetic methods of amino acids bearing a fluorinated olefins. There are various successful syntheses that afford fluorinated olefins, and some have significant methodological value to synthetic chemists in the preparation of fluorinated amino acid libraries.

\section{Monofluoroolefinic Amino Acid Derivatives}

The monofluorovinyl moiety is often considered isosteric to the peptide bond. As such, due to the electronic similarity, it can replace the amide bond in peptides. Furthermore, the incorporation of fluorovinyl moieties in simple amino acids can strongly affect their bioactive properties and, therefore, this is a common strategy used in the design and synthesis of amino acid derivatives.

The early synthesis of (E)-6-(fluoromethylene)- $m$-tyrosine was reported by McDonald et al. in $1984 .{ }^{11}$ The first step required the bromination followed by further fluorination by $\mathrm{KHF}_{2}$. Compound 2 was obtained in $54 \%$ yield and was further treated with triethyl phosphonoacetate in the presence of $\mathrm{NaH}$ to yield 3, as a mixture of $Z$ - and E-isomers in 8:1 ratio and $80 \%$ yield. After subsequent bromination and dehydrobromination by piperidine, compound 4 was obtained that was further treated with LDA to give the $E$-bromide 5. Subsequent reaction of bromide 5 with ammonia in DMSO gave amine 6 in 20\% yield. After deprotection of 6 the final product 7 bearing monofluorovinyl moiety was synthesized as a colorless powder in good $86 \%$ yield (Scheme 1). 

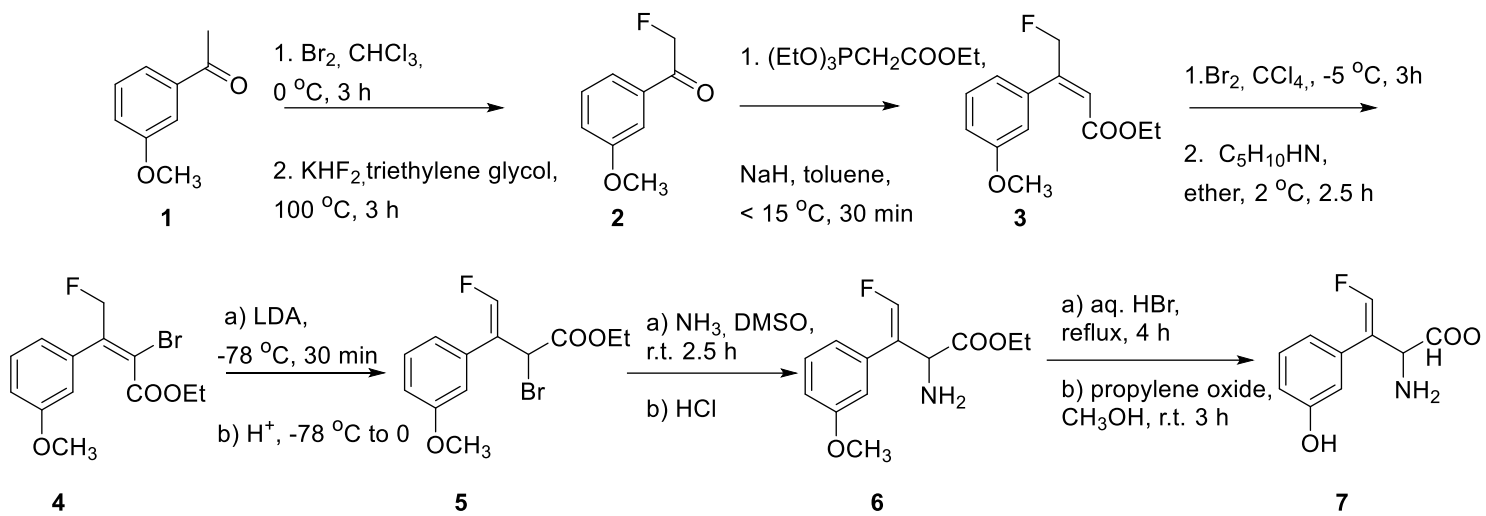

Scheme 1. Multi-step synthesis of (E)-6-(fluoromethylene)-m-tyrosine (7).

McDonald's procedure employed a Wittig-type reaction and led to the E-isomer only. One year later, the same group offered another method called the "isocyanoacetate route" which gave both isomers. ${ }^{12}$ This procedure involved fluoroketone $\mathbf{8}$ as a starting material which was first treated with phenyltrimethylammonium tribromide to form product 9 in $87 \%$ yield. Subsequent, condensation with ethyl isocyanoacetate in the presence of $\mathrm{Cu}_{2} \mathrm{O}$ as catalyst gave a mixture of diastereoisomers $\mathbf{1 0}$. Next, the formed oxazoline 10 was protonated by trifluoroacetic acid which led to oxazoline ring opening. Furthermore, activated zinc has been used and compounds 11 and $\mathbf{1 2}$ were formed. The last step involved the refluxing in $47 \%$ aqueous solution of $\mathrm{HBr}$ and the treatment of propylene oxide. It finally resulted in the (E)-isomer $\mathbf{1 3}$ as a colorless powder and the (Z)-isomer 14 as a yellowish powder in equal $28 \%$ yields (Scheme 2 ).

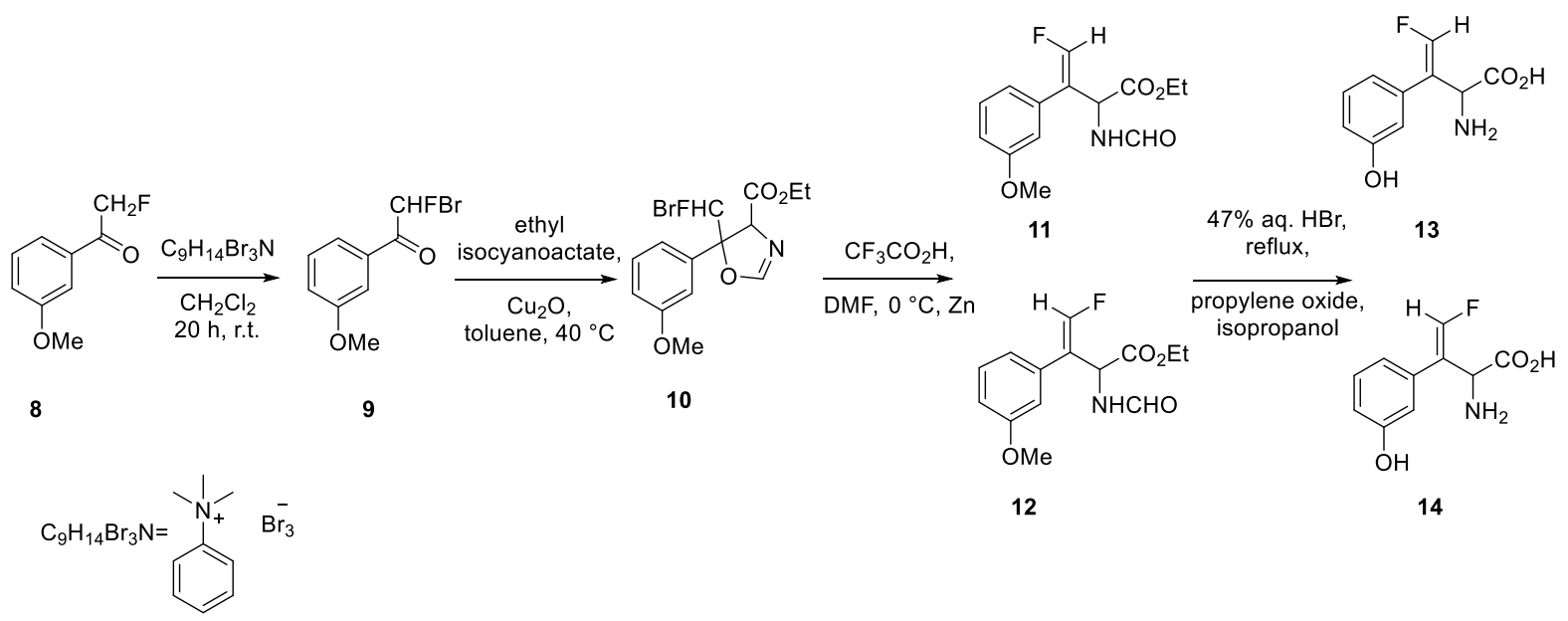

Scheme 2. Synthesis of (E)- and (Z)- fluoromethylene- $m$-tyrosine via the isocyanoacetate route.

The synthesis of 3-fluorovinylglycine (18) was reported by Thornberry et al. ${ }^{13}$ (Scheme 3). The monofluorovinyl group from starting material 2-fluoroacrolein (15) has been transferred in the reaction with 4,4'-dimethoxybenzhydrylamine (16) into the desired product. First, the aldehyde was transformed into cyanoamine and subsequent treatment with refluxing $6 \mathrm{~N} \mathrm{HCl}$ and elution with aqueous pyridine yielded the desired monofluorovinyl compound 18 in $25-30 \%$. 


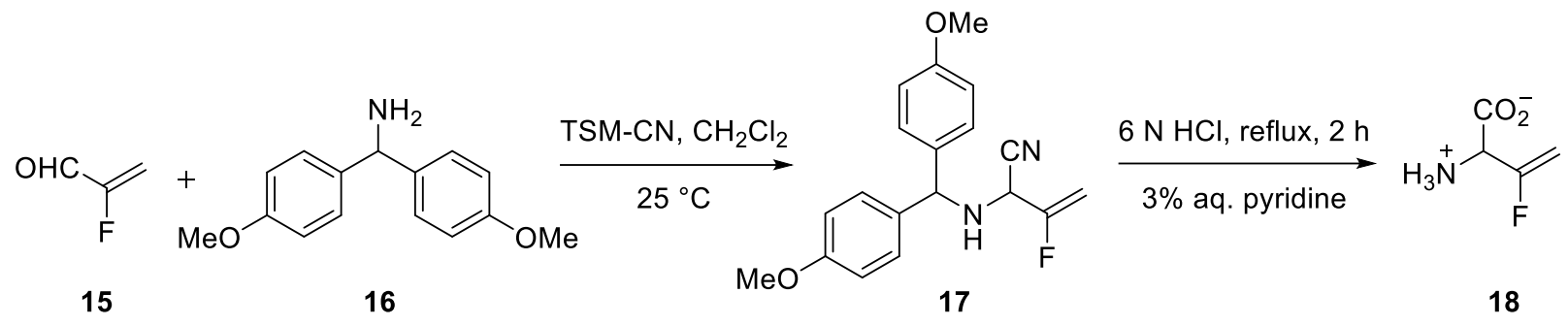

Scheme 3. Synthesis of 3-fluorovinylglycine (18).

The method established by McDonald was further studied by Lacan et al. ${ }^{14}$ The protected derivative of 19 was prepared according to the previously described Wittig-type reaction. Subsequently, treatment of the starting material $\mathbf{1 9}$ with trifluoroacetic anhydride yielded (E)- and (Z)-trifluoroacetyl derivatives 20 and $\mathbf{2 1}$ in the $85: 15$ ratio. Next, these isomers were separated by subjecting them to $\alpha$-Chymotrypsin. This enzyme specifically catalyzed only the hydrolysis of the $(E)$-isomer $\mathbf{2 1}$ while there was no interaction between Chymotrypsin and (Z)-isomer 20. As a result, the compounds $\mathbf{2 2 a}$ and $\mathbf{2 2} \mathbf{b}$ were formed. Deprotection was achieved by $\mathrm{HBr}$-mediated hydrolysis and yielded $\mathbf{2 3 a}$ and $\mathbf{2 3 b}$ (or $\mathbf{2 3 c}$ and $\mathbf{2 3 d}$ ) in equal amounts. The product mixture was separated by HPLC (Scheme 4).

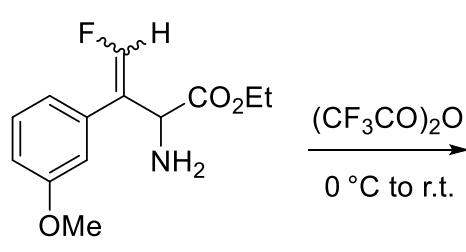

19<smiles>CCOC(=O)C(NC(=O)C(F)(F)F)C(=CF)c1cccc(OC)c1</smiles>

20
21
Chymotrypsin DMF, $\mathrm{AcONH}_{4}$<smiles>[X]C([X])=C(c1cccc(O)c1)C(N)C(=O)O</smiles>

23

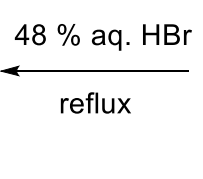

22a $\mathrm{R}=\mathrm{H}(S)$ 22b $\mathrm{R}=\mathrm{Et}(R)$

Scheme 4. Synthesis of (E)- and (Z)-3-fluoromethylene- $m$-tyrosines.

McDonalds's group continued studies on synthetic methodology, and in 1985 proposed the synthesis of (E)- $\beta$-fluoromethyleneglutamic acid according to a similar method. ${ }^{15}$ The final product was prepared in 11 steps from ethyl 3,3-dimethylacrylate (24) (Scheme 5). First, the substrate was brominated (total 57\% yield) and then fluoride exchange took place. The prepared product $\mathbf{2 5}$ was obtained as a mixture of isomers in $50 \%$ yield. Further the bromination and subsequent dehydrobromination process transformed 25 into 26 in $69 \%$ yield. Then, isomerization led to form only the $E$-isomer $\mathbf{2 7}$. The exchange of bromine with phthaloyl dichloride in the presence of dimethyl sulfoxide saturated with ammonia and 4-aminopyridine enabled to obtain $N$ protected amino acid derivative $\mathbf{2 8}$ in $13 \%$ yield. After bromination of methyl group, the compound $\mathbf{2 9}$ was synthesized as a mixture of $Z$ - and $E$ - isomers in 2:1 ratio. Finally, the use of sodium cyanide yielded $\mathbf{3 0}$, 
treatment of which with concentrated $\mathrm{HCl}$, then propylene oxide and isopropanol, after several days allowed the formation of the target product $\mathbf{3 1}$ in an excellent $95 \%$ yield. This multistep synthesis gave access to desired fluoro derivative of glutamic acid.

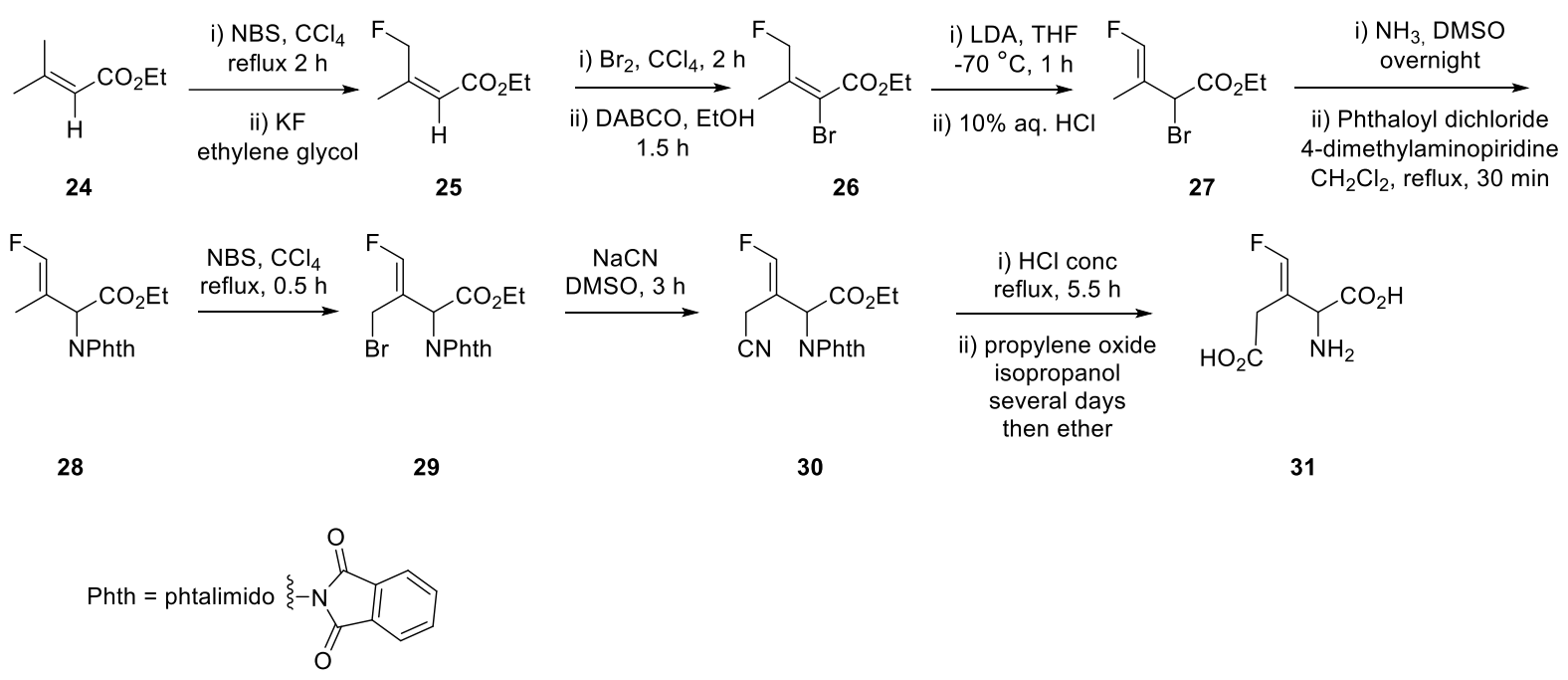

Scheme 5. Multi-step synthesis of (E)-6-fluoromethyleneglutamic acid.

Similarly, McDonald and Bey presented a general route to fluoroallyl amino acids by modifying the $\mathrm{N}$ protected substrate bearing fluorovinyl moiety. ${ }^{16}$ The starting phthalimide $\mathbf{3 2}$ (Scheme 6) was treated with NBS affording bromide as a mixture of $E / Z$-isomers. Next, only the Z-isomer $\mathbf{3 3}$ was used in the reaction with sodium cyanide and was transformed to the corresponding nitrile 34. A subsequent hydrolysis with hydrochloric acid yielded amino acid $\mathbf{3 5}$ as a final product.

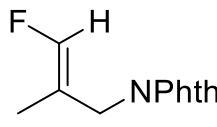

32

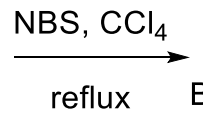<smiles>F/C=C(/CBr)CNc1ccccc1</smiles>

33

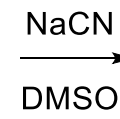

DMSO NC

$$
34
$$

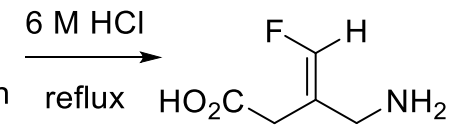

35

Scheme 6. Synthesis of (Z)-fluorovinyl amino acid using phthalimide method.

The synthesis of amino-fluoro-hexenoic acids has been studied by Kolb et al. They used 5-ethenyl-2pyrrolidynone (36) as starting material. ${ }^{17}$ In the first step, substrate reacted with HF in the presence of pyridine and NBS to obtain (bromofluoroethyl)pyrrolidinones as a mixture of isomers 37/38 in ratio 25:75. The next step involved elimination of $\mathrm{HBr}$ and led to the formation of fluorovinyl compounds $\mathbf{3 9}$ and $\mathbf{4 0}$ in $50 \%$ yield. Finally, after separation of the isomers $\mathbf{3 9}$ and $\mathbf{4 0}$ and acid hydrolysis gave the desired compounds $\mathbf{4 1}$ and $\mathbf{4 2}$, respectively (Scheme 7 ). 


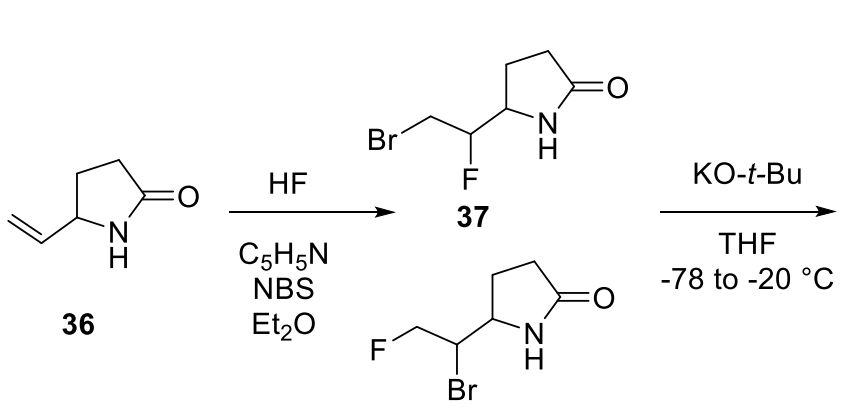

38

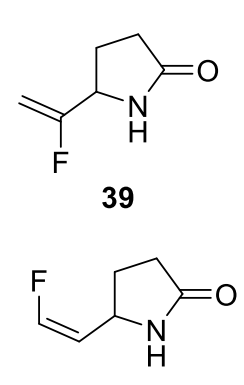

40<smiles>C=C(F)C([NH3+])CCC(=O)O</smiles>

$1 \mathrm{~N} \mathrm{HCl}$<smiles>[NH3+]C(/C=C\F)CCC(=O)O</smiles>

42

Scheme 7. Synthesis of 4-amino-5-fluoro-5-hexenoic acid (41) and (Z)-4-amino-6-fluoro-5-hexenoic acid (42) hydrochloride salts.

The synthesis described above was further investigated by Silverman et al. in $1996 .{ }^{18}$ They also proposed the synthetic scheme to yield compound $\mathbf{4 2}$ (Scheme 7). In contrast to the Kolb's synthesis, they isolated the (E)-(5-fluorovinyl)-2-pyrrolidinone (43) which is a precursor to the desired (E)-4-amino-6-fluoro-5-hexenoic acid (44) (Scheme 8).

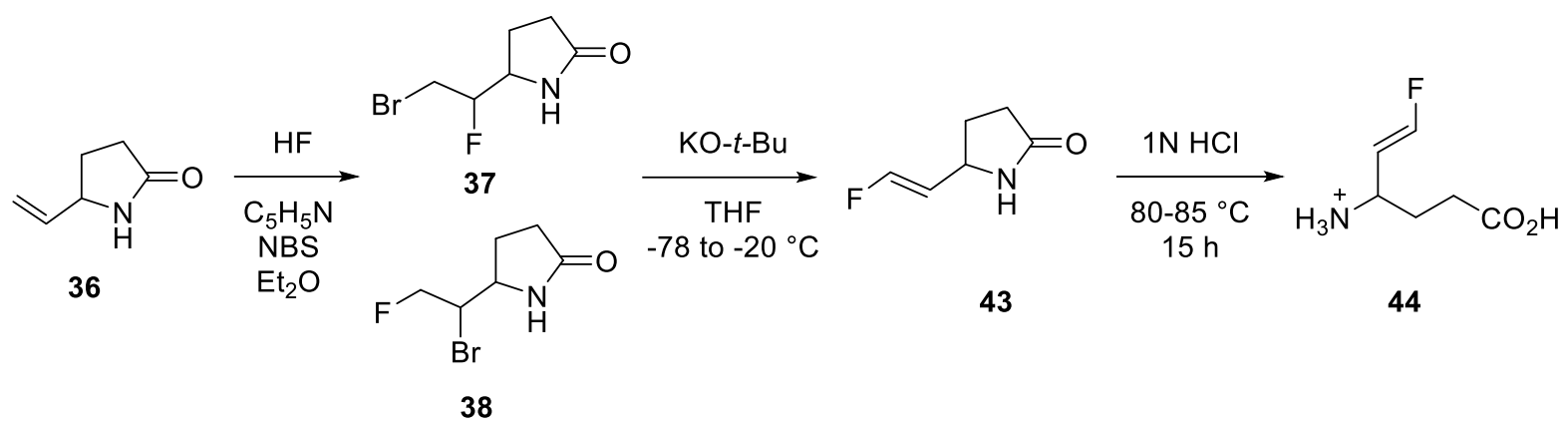

Scheme 8. Synthesis of (E)-4-amino-6-fluoro-5-hexenoic acid.

McCarthy et al. published the synthesis of fluorovinyl amino acids according to HWE (Horner-WadsworthEmmons) procedure. ${ }^{19}$ The starting aldehyde $\mathbf{4 5}$ was condensed with McCarthy's reagent to form vinylsulfone, which was subsequently treated with $\mathrm{Bu}_{3} \mathrm{SnH}$. The mixture of isomers $\mathbf{4 7}$ and $\mathbf{4 8}$ was obtained in 60 and $11 \%$ yields, respectively (Scheme 9). These isomers were separated and treated with sodium methanolate. The isopropyl group was removed by $p$-toluenesulfonic acid and $\mathbf{5 0}$ and $\mathbf{5 4}$ were obtained in 50 and $34 \%$ yield, respectively. Finally, the alcohols $\mathbf{5 0}$ and $\mathbf{5 4}$ were oxidized to the carboxylic acid in the presence of PCC and the Boc protective group was removed. Products $\mathbf{5 2}$ and $\mathbf{5 6}$ were obtained in $\mathbf{7 5}$ and $\mathbf{7 8 \%}$ yields, respectively. 


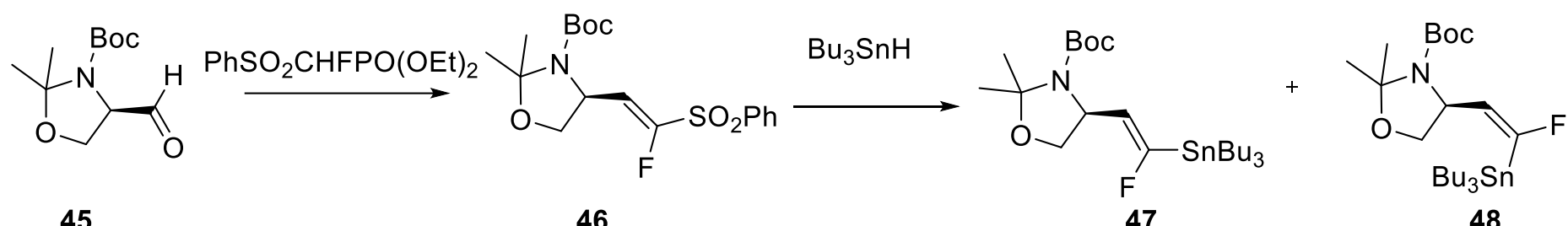

45

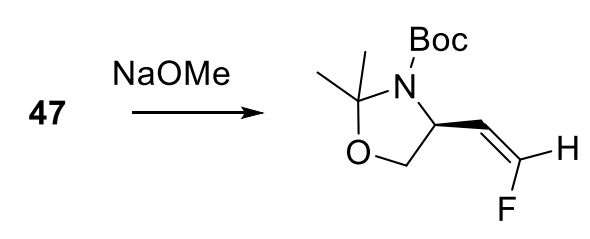

49

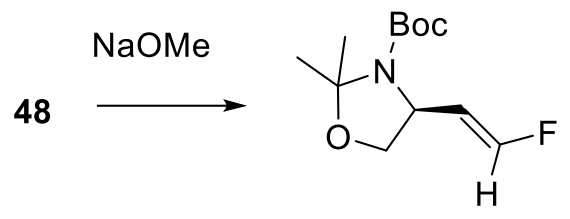

53

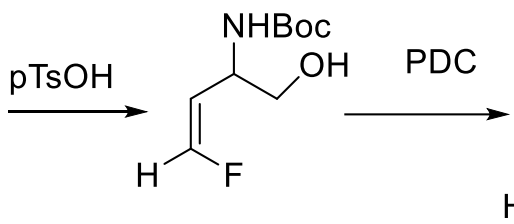

50<smiles>CC(C)(C)OC(=O)C(N)/C=C/F</smiles>

51<smiles>N[C@@H](/C=C/F)C(=O)O</smiles>

52

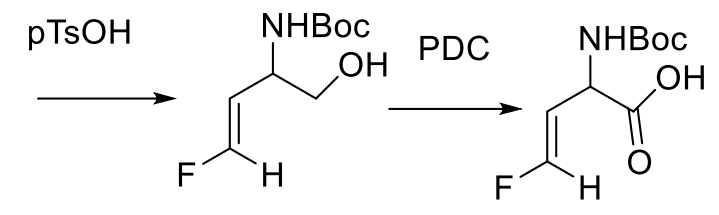

54

55<smiles>[NH3+]C(/C=C/F)C(=O)O</smiles>

56

Scheme 9. Synthesis of amino acids $\mathbf{5 2}$ and $\mathbf{5 6 .}$

The research presented by Laue et al. involved the enantioselective synthesis of fluoroolefin amino acid derivatives. ${ }^{20}$ Fluoroolefins are known as the amide bond isosteres, where the carbon - fluorine bond mimics the carbonyl moiety. ${ }^{21}$ As a starting material camphor derivatives of glycine 57a and alanine 57b have been used (Scheme 10). The first step involved alkylation with 3-bromo-2-fluoropropene (58) and formation of alkylated product 59a in $86 \%$ and 59b in 64\% yields, respectively. Further transamination, acid hydrolysis and treatment with propylene oxide allowed the formation of $(R)-(+)-2$-amino-4-fluoropent-4-enoic acid (61a) (59\% yield and $94 \%$ ee) which is as an isostere for asparagine and $(R)-(+)$-2-amino-4-fluoro-methylpent-4-enoic acid (61b) in $59 \%$ and $61 \%$ ee.

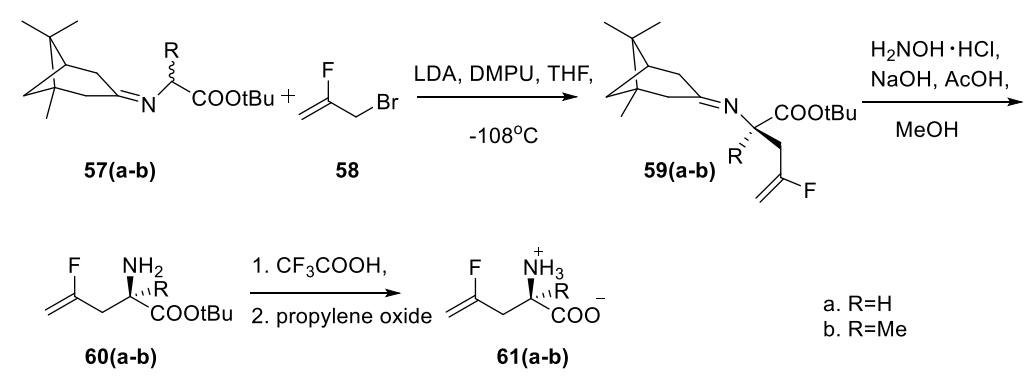

Scheme 10. Enantioselective synthesis of asparagine isostere $61 \mathrm{a}$ and its analogue $\mathbf{6 1 b .}$

The earlier described method was further investigated also by Laue et al. $^{22}$ The first step involved alkylation of compound 62 by 3-bromo-2-fluoropropene $(58)$ at $-78{ }^{\circ} \mathrm{C}$ and allowed the formation of 63 in $73 \%$ yield and diastereoselectivity above $97 \%$. Further acid hydrolysis caused partial racemization and compound 64 was obtained with $83 \%$ enantioselectivity. Finally, deprotection of carboxylic group by $\mathrm{CF}_{3} \mathrm{CO}_{2} \mathrm{H}$ led to desired (S)-2-amino-4-fluoropent-4-enoic acid (65) (Scheme 11). 


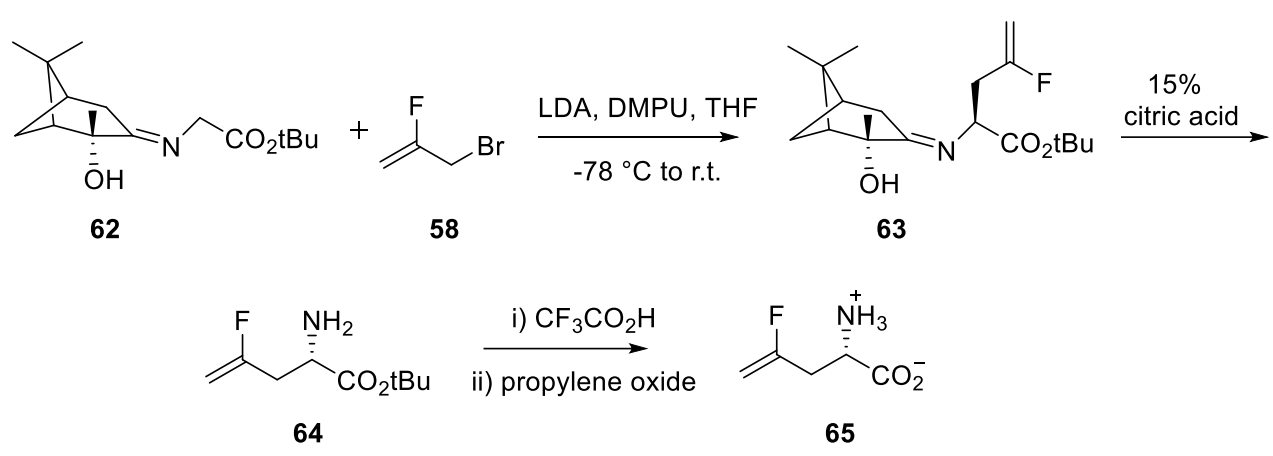

Scheme 11. Synthesis of $\gamma$-fluorinated $\alpha$-amino acid.

Another example of synthetic approach has been presented by Berkowitz et al. ${ }^{23}$ They reported the threestep synthesis of six fluorovinyl amino acid derivatives employing Horner-Wadsworth-Emmons reaction protocol. As a starting reactant diethyl $\alpha$-fluoro- $\alpha$-(phenylsulfonyl)-methyl phosphonate (67) (McCarthy's reagent) was used with corresponding aldehydes 66 a-f in the presence of the LiHMDS as a strong base. The reaction was carried out in $-78^{\circ} \mathrm{C}$ and led to (E)- $\alpha$-fluorovinyl sulfones 68 a-f in good to excellent yield (52-93\%) and unusual diastereoselectivity - each compound was obtained as a single geometric isomer (E). The next step included the stereospecific interchange of sulfone to stannane 69. The last step involved protodestannylation, deprotection of amine and carboxylic group with hydrochloric acid and allowed formation of (Z)- $\alpha$-(2'fluoro)vinyl amino acids 70 a-f in yields ranging from $52 \%$ for 70 and $93 \%$ for DOPA derivative 70d (Scheme 12).

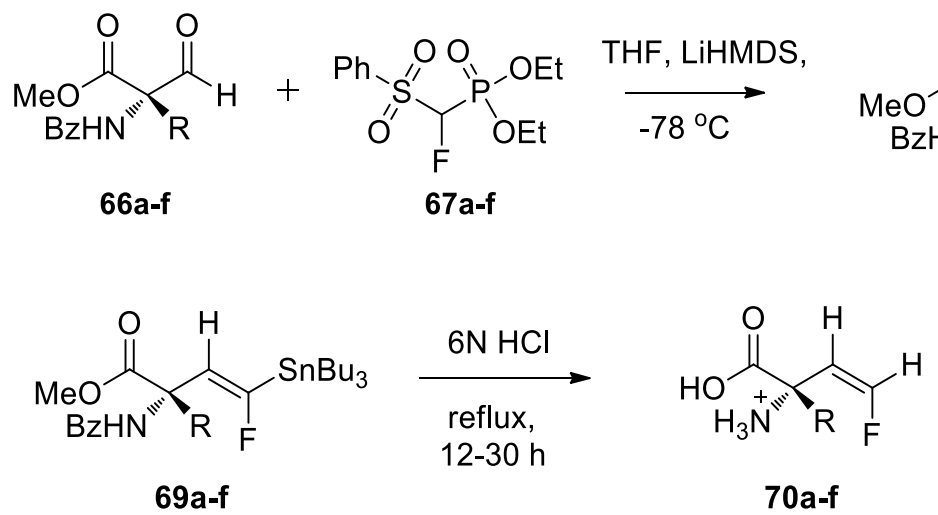
a) $\mathrm{Me}$
b) $\mathrm{Ph}-\mathrm{CH}_{2}-$
c) $p$-TBSO-Ph- $\mathrm{CH}_{2}-$
d)

e) $\mathrm{BzHN}-\left(\mathrm{CH}_{2}\right)_{4}^{-}$

f) $\mathrm{MeOOC}-\mathrm{CH}_{2}^{-}$

Scheme 12. Synthesis of amino acids with (2'Z)-fluorovinyl moiety.

In 2004 Qiu et al. described for the first time the dehydrofluorination process of $(2 S, 4 S)$-tert-butyl- $N$-tertbutoxycarbonyl-4-difluoromethylpyroglutamate (71). ${ }^{24}$ The starting material $\mathbf{7 1}$ was synthesized from trans-4hydroxy-L-proline. ${ }^{15,16}$ The reaction course was tested with the use of different bases in $\mathrm{CH}_{2} \mathrm{Cl}_{2}$. Triethylamine led to the formation of the desired product in $90 \%$ yield, while the use of pyridine yielded $\mathbf{7 2}$ only in less than $3 \%$. The effect caused by the use of different solvent in the reaction was also investigated in presence of $\mathrm{NEt}_{3}$ as a base. The best results (90\% yield) were obtained for $\mathrm{CH}_{3} \mathrm{CN}$ and $\mathrm{CH}_{2} \mathrm{Cl}_{2}$. Finally, deprotection with $\mathrm{CF}_{3} \mathrm{CO}_{2} \mathrm{H}$ allowed getting the desired 4-monofluoromethylenyl-L-pyroglutamic acid (73) in 72\% yield (Scheme 13). 


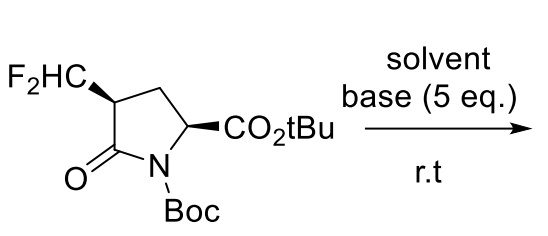

71<smiles>CC(C)(C)OC(=O)[C@@H]1C/C(=C/F)C(=O)N1C(=O)O</smiles>

72<smiles>CCCCCCCCCC(=O)O</smiles>

73

Scheme 13. Synthesis of 4-monofluoromethylenyl-L-pyroglutamic acid by the dehydrofluorination reaction.

Shendage et al. reported the selective and efficient synthesis of $\gamma$-fluoro- $\alpha$-amino acids from (S)-Boc-BMI $\mathbf{7 4 a - \mathbf { b } ^ { 2 7 }}$ (Scheme 14). The first step included asymmetric alkylation of 74a-b with fluorovinyl tosylate in the presence of LDA as a base and led to the products 75a-b in 89 and $84 \%$ yield, respectively. These compounds were then transformed with the use of $\mathrm{HCl} / \mathrm{MeOH} / \mathrm{H}_{2} \mathrm{O}$ to $N^{\prime}$-methylamides $76 \mathbf{a}-\mathbf{b}$ in 43 and $63 \%$ yields, respectively. The final products $77 \mathbf{a}-\mathbf{b}$ were obtained after basic hydrolysis and treatment of propylene oxide in ethanol. After basic hydrolysis of the amide bond of 76a, partial racemization was observed in the formed compound 77a. To minimize this effect, 75a was treated with phthalic anhydride and oxalyl chloride which allowed the formation of the amide $\mathbf{7 8 a}$ in $89 \%$ yield. The amide bond was further removed by thermal decomposition of the in situ generated $N^{\prime}$-nitrosoamide and the desired product $\gamma$-fluoro- $\alpha$-amino methyl ester 79a was obtained in $91 \%$ yield (Scheme 14).

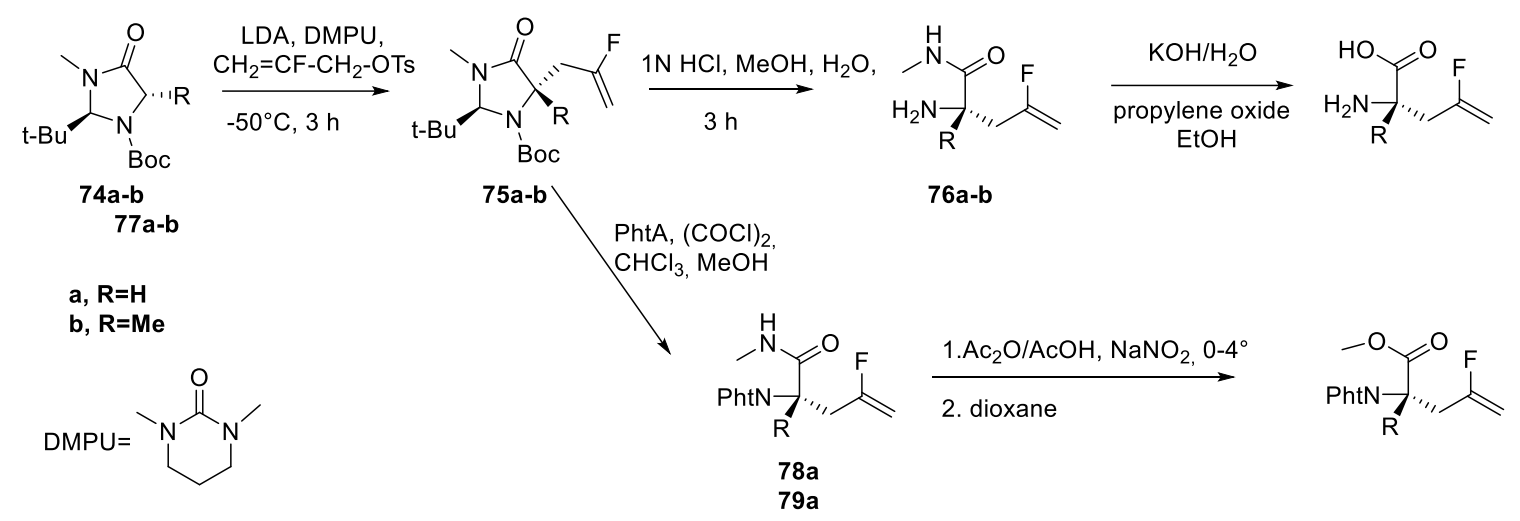

Scheme 14. Asymmetric synthesis of $\gamma$-fluoro- $\alpha$-amino acids.

In 2013 Haufe $^{28}$ reported the synthesis of fluoroallyl amino acid derivatives which were used to synthesize 2-amino-4-fluoropent-4-enoic acid esters 81a-b (Scheme 15). This process included alkylation of imine 80a with 2-fluoroallyl bromide and imine $\mathbf{8 0 b}$ with corresponding tosylate. The desired products $\mathbf{8 1 a}$ and $\mathbf{8 1} \mathbf{b}$ were obtained in 83 and $96 \%$ yields, respectively.<smiles>O=C([O-])CN=C(c1ccccc1)c1ccccc1</smiles>

$80 \mathrm{a} R=\mathrm{Me}$ $80 \mathrm{~b} R=t-B u$

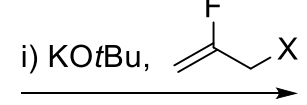

ii) $15 \%$ citric acid

$\mathrm{X}=\mathrm{Br}$ $\mathrm{X}=\mathrm{OTs}$<smiles>[R]OC(=O)C(N)CC(=C)F</smiles>

81a $\mathrm{R}=\mathrm{Me}$ 81b $R=t-B u$

Scheme 15. Synthesis of 4-fluoro-2-amino acid esters $\mathbf{8 1 a - b .}$ 
Later, Haufe developed the synthesis which involved methyl or ethyl benzhydrylidene glycinates $\mathbf{8 2 a}$ and $\mathbf{8 2} \mathbf{b}$ as starting materials (Scheme 16$).{ }^{28}$ As a reagent, the use of 2-fluoro-4-iodobut-1-ene (83b) led to the formation of $\mathbf{8 4 a}$ and $\mathbf{8 4 b}$ with rather low yields from 11 to $16 \%$, respectively. 2-Fluoro-4-tosyl-but-1-ene (83a) allowed to obtain higher quantities of $\mathbf{8 4 a}$ and $\mathbf{8 4 b}$. The final step included deprotection of carboxylic group and formation of the 2-amino-5-fluorohex-5-enoic acid in $20 \%$ yield for $\mathrm{R}=$ Me or $56 \%$ yield for $\mathrm{R}=\mathrm{Et}$ (85).<smiles>[X]CCC(=C)F</smiles>

82a $\mathrm{R}=\mathrm{Me}$ 82b R=Et 83a $X=O T s$ $83 b X=1$<smiles>C=C(F)CCC(N=C(c1ccccc1)c1ccccc1)C(=O)O</smiles>

84a $\mathrm{R}=\mathrm{Me}$ 84b $R=E t$

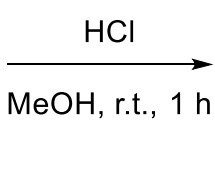<smiles>C=C(F)CCC([NH3+])C(=O)[O-]</smiles>

85

Scheme 16. Synthesis of fluoroallyl amino acid by alkylation of imine.

Due to the low yields of the previous synthesis, Haufe prepared methyl N-Boc-(S)-2-amino-5-fluorohex-5enoate (88) according to Jackson's procedure with zinc reagents. ${ }^{29}$ The alanine iodo-derivative 86 in the presence of activated zinc led to the formation of intermediate $\mathbf{8 7}$ and its further treatment with $\mathrm{CuBr}$ and alkylation with tosylate yielded product 88 in $61 \%$ (Scheme 17).<smiles>COC(=O)C(N)CI</smiles>

86

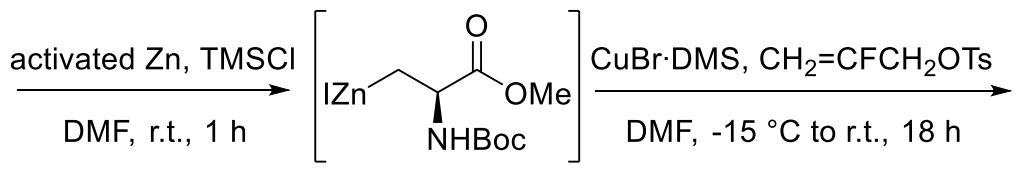

87<smiles>C=C(F)CCC(N)C(=O)OC(C)(C)C</smiles>

88

Scheme 17. Zinc-activated synthesis of fluorinated allylalanine derivative $\mathbf{8 8 .}$

Furthermore, Haufe et al. synthesized amino acid derivatives with monofluorovinylic side chain. ${ }^{30}$ The first step involved oxidation of the starting material by $\mathrm{SeO}_{2}$ (Scheme 18). Further condensation of the generated fluorinated alcohol $\mathbf{9 0}$ with $\mathrm{N}$-Boc-glycine allowed the formation of the amino ester enolate. Subsequently, the Claisen rearrangement occurred affording the desired product 92 in $86 \%$ yield.

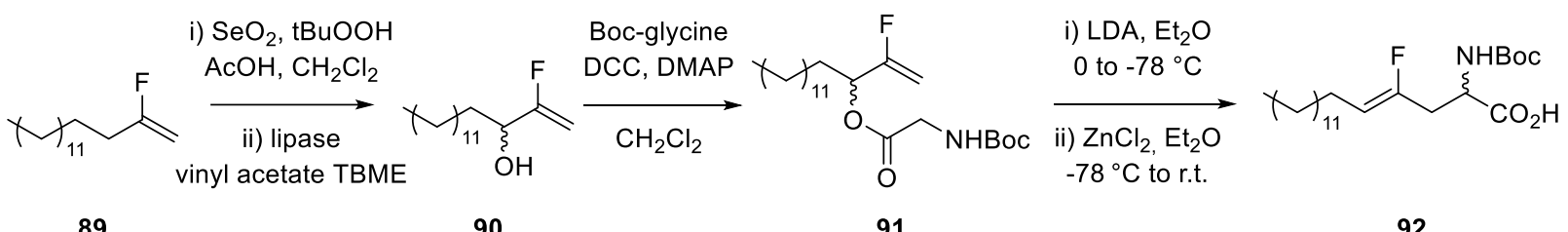

Scheme 18. Synthesis of amino acid 92.

The synthesis of $\beta, \gamma$-unsaturated amino acids has been reported by Berkowitz. ${ }^{31}$ In the proposed procedure the carboxyl and amino groups are retained, but also the fluorovinyl side chain bonded to the $\alpha$ carbon is present. In 2004 Berkowitz et al. described the synthesis of such compounds by the Horner- 
Wadsworth-Emmons reaction using the McCarthy's reagent (diethyl-2-fluoro-1-(phenylsulfonyl)methyl phosphonate, 67). ${ }^{23}$ The product contained fluorine atom in the 2' position of vinylic group 96 (Scheme 19). This method was further investigated to obtain fluorine at the $1^{\prime}$ position of the vinylic fragment 99 . The electrophilic fluorinating agent $\mathbf{1 0 0}$ was used (method B) compared to previous method in which nucleophilic fluorination with 95 took place (method A).

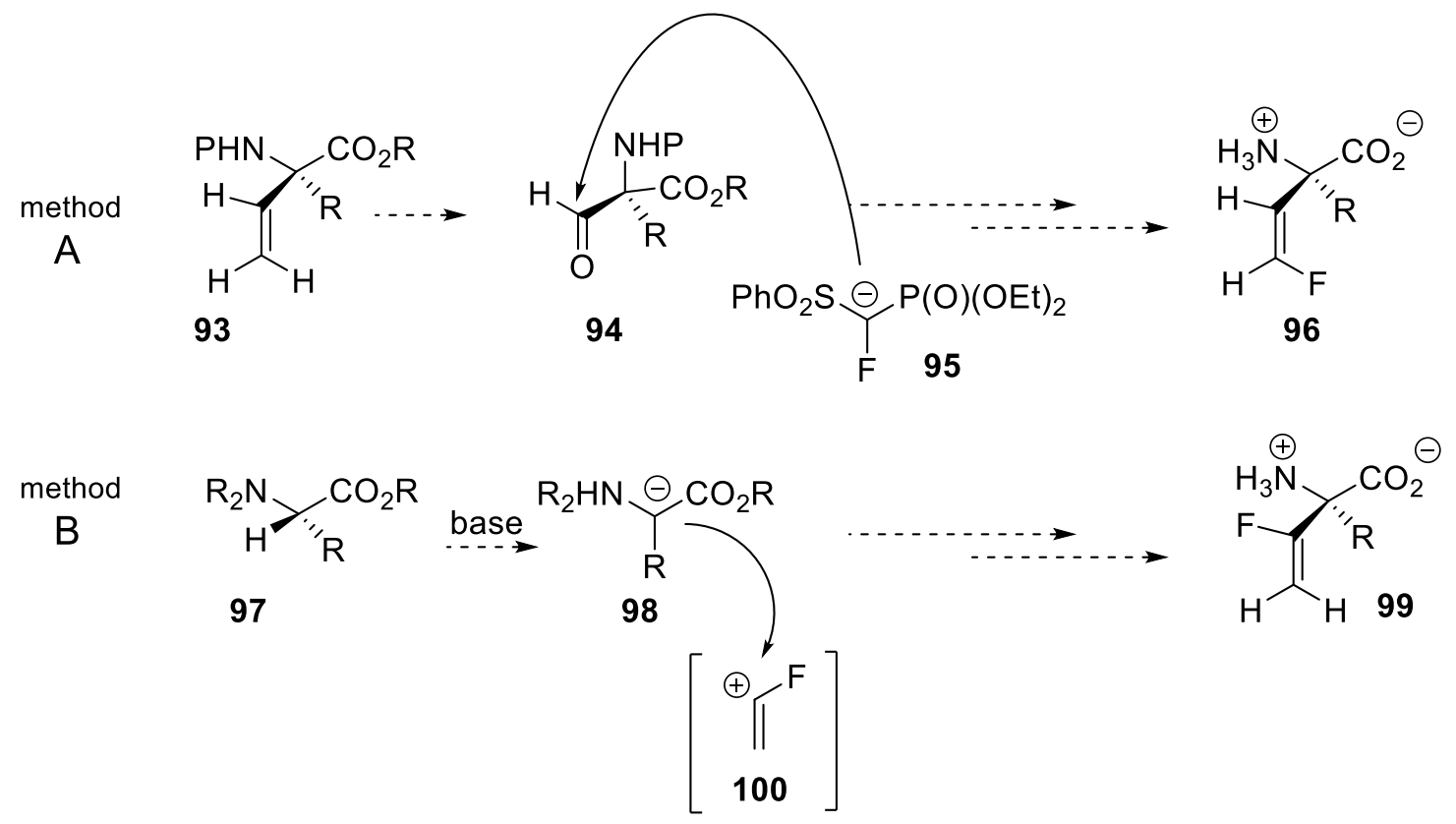

Scheme 19. Synthesis of fluorovinyl amino acids.

The amino acids derivatives (Scheme 20, 101a-j) reacted with LiTMP and sulfone 100 to form compounds $102 \mathrm{a}-\mathrm{j}$ in 60 to $91 \%$ yields. Subsequently they were treated with $\mathrm{Bu}_{3} \mathrm{SnH}$ in the presence of $\mathrm{AlBN}$ and the products 103a-i were obtained in good yields (70-91\%). Finally, the $-\mathrm{SnBu}_{3}$ group was removed by acid hydrolysis and the carboxylic moiety was deprotected. The desired $\alpha$-(1'-fluoro)vinyl amino acids hydrochlorides 99 a-f and $\mathbf{9 9 k}$-I were obtained in 52 to $99 \%$ yields.
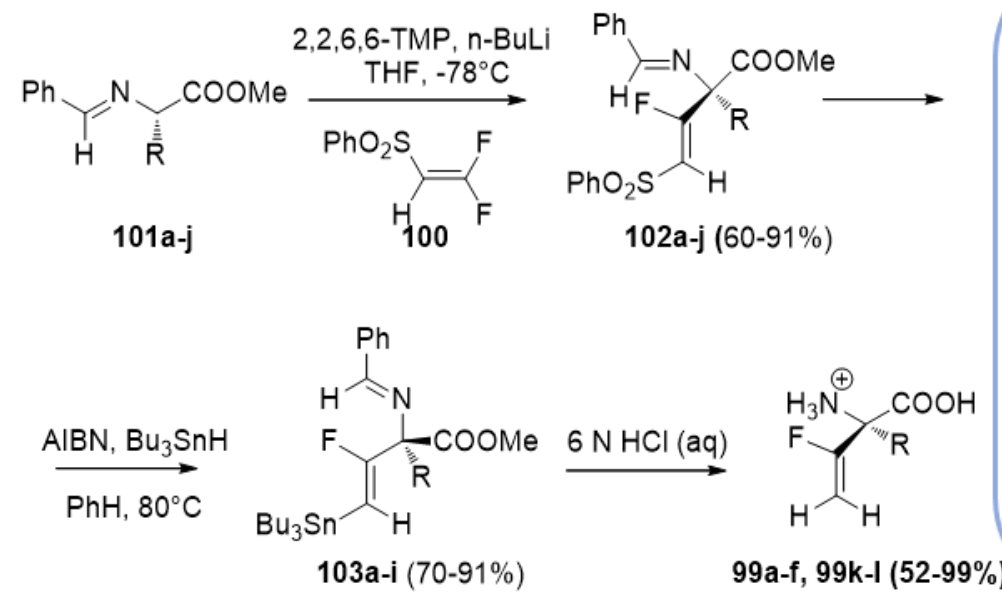

99a-f, 99k-I (52-99\%)

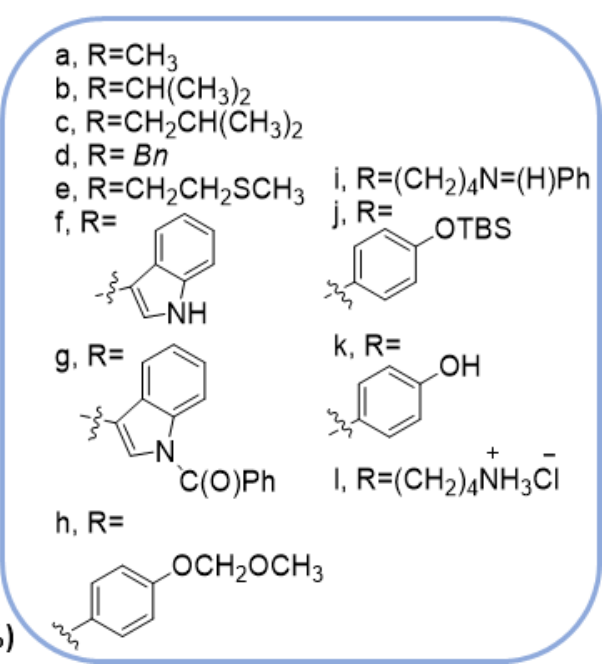

Scheme 20. Synthesis of $\alpha$-(1'-fluoro) vinyl amino acids. 


\section{Difluoro- and Trifluoro Amino Acid Derivatives}

Access to the difluoro- and trifluorofinyl derivatives is discussed below. The di- and trifluorovinyl groups are very special components in medicinal chemistry and can be widely used in the design of drugs, owing to their metabolic stability.

The synthesis of 4-amino-6,6-difluoro-5-hexenoic acid from 4-oxobutanoic acid tert-butyl ester, was described by Kolb et al. (Scheme 21). ${ }^{17}$ Ozonolysis of the starting ester afforded the aldehyde 105 . that can be treated with 1,1-difluoroethene to give the difluorinated alcohol 106. Furthermore, alcohol 106 can be converted into the phthalimide $\mathbf{1 0 7}$ that, on mild acid hydrolysis in the presence of hydrazine, gives the amino ester hydrochloride $\mathbf{1 0 8}$ which, after ester hydrolysis, was transformed to the desired product 109.

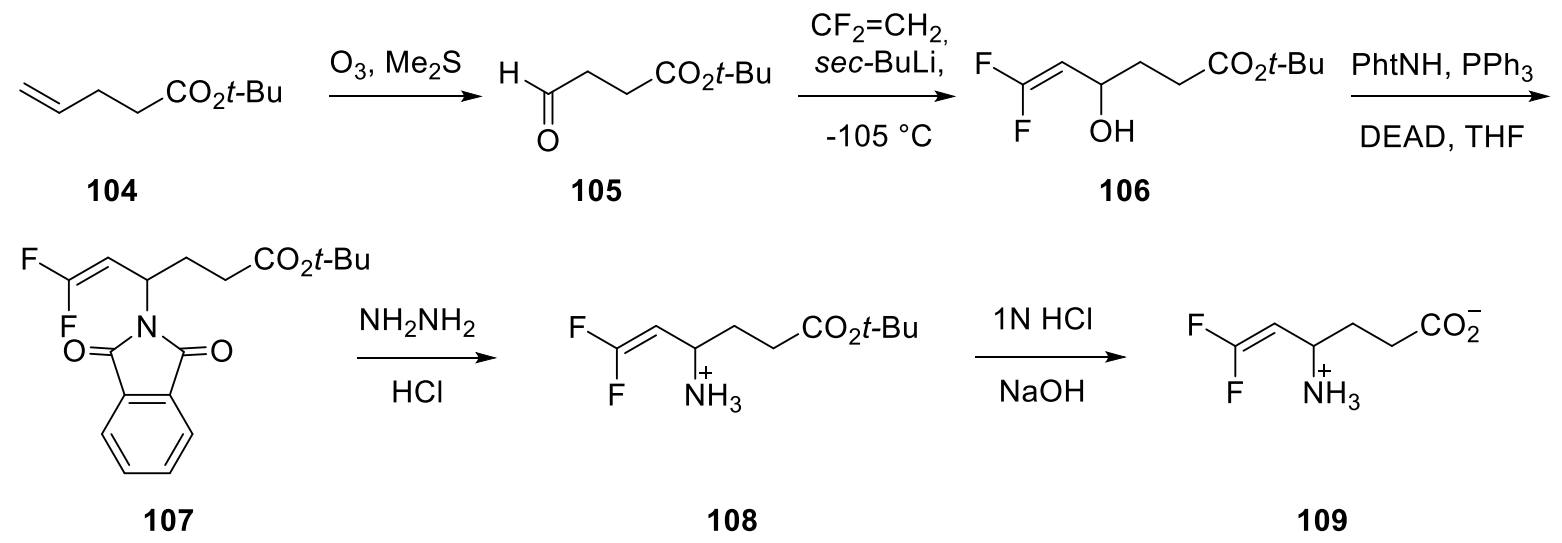

Scheme 21. Synthesis of 4-amino-6,6-difluoro-4-hexenoic acid 109.

Qui et al. proposed the synthesis of benzyl (2S)-N-Boc-4-difluoromethyleneprolinate (111) (Scheme 22). ${ }^{25}$ The reaction proceeded by addition of $\mathrm{CF}_{2} \mathrm{Br}_{2}$ to the carbonyl moiety of the substrate 110 and subsequent treatment with zinc and HMPT which yielded the target derivative of proline $\mathbf{1 1 1}$ in $48 \%$ yield. This compound has been obtained as an intermediate for further synthesis of its hydrogenated analogue $N$-Boc-cis-4-difluoromethyl-L-proline.
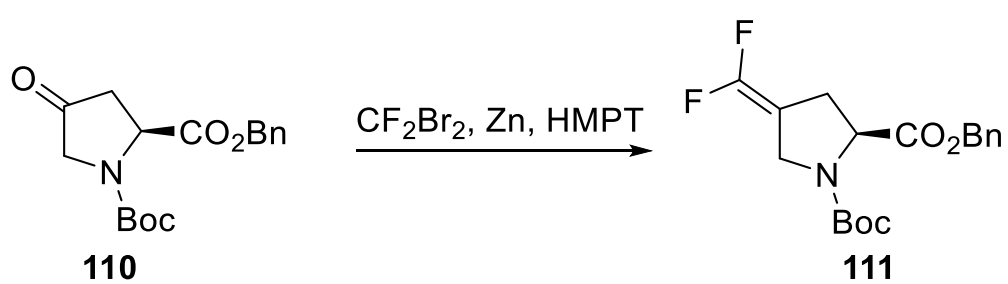

Scheme 22. Synthesis of benzyl (2S)-N-Boc-4-difluoromethyleneprolinate 111.

In 2003 Pan et al. synthesized the unsaturated difluoro-substituted amino acid 115 (Scheme 23) using a Horner-Wadsworth-Emmons reaction as a key reaction step. Further treatment with cerium ammonium nitrate and acid hydrolysis in the final step yielded the amino acid $\mathbf{1 1 5}$ with a difluoroalkene moiety. ${ }^{32}$ 


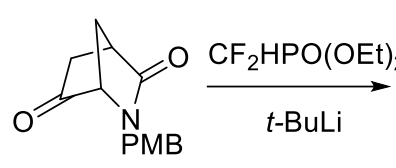

112

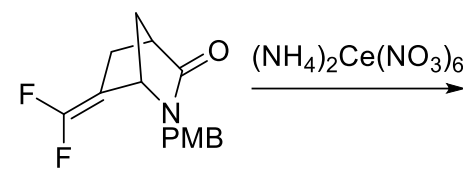

113

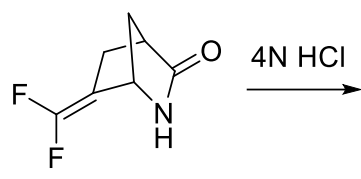

114

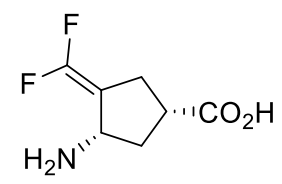

115

Scheme 23. Synthesis of (1S,3S)-3-amino-4-difluoro-methylene-1-cyclopentanoic acid (115).

The synthesis of 4-difluoromethylene proline 119 was described by Ichikawa et al. ${ }^{33}$ The three-step procedure involved treating the starting material 116 with $\mathrm{NaH}$, removal of the PMB group with DDQ and further oxidation of the generated alcohol 118 with $\mathrm{NaClO}_{2}$ in the presence of TEMPO. This route led to the desired product 119 in 93\% yield and 99\% enantioselectivity (Scheme 24).

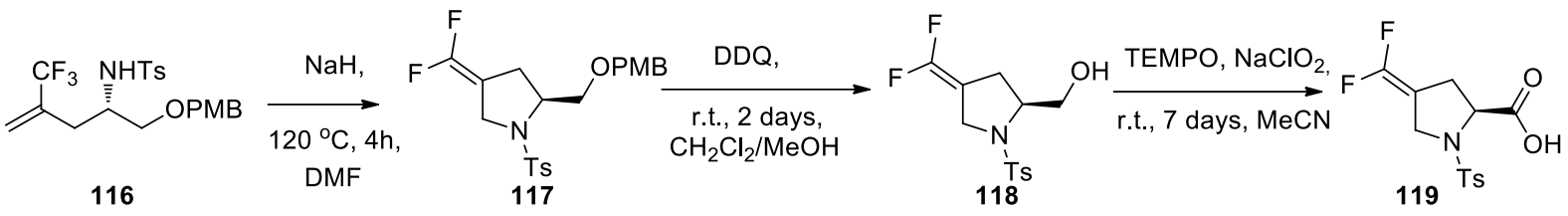

Scheme 24. Synthesis of 4-difluoromethylene proline 119.

The synthesis of ethyl 3,3-difluoro-2- $N$-tosylamino-2-propenoate (121) (Scheme 25) was presented by Katagiri et al. ${ }^{34}$ The reaction of aziridine $\mathbf{1 2 0}$ with Grignard reagent led to the formation of the desired amino acid derivative 121 as the major product (68\%) together with a minor side product 122 (16\%).

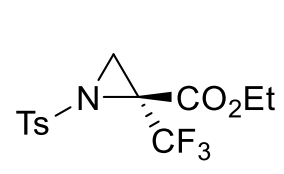

120

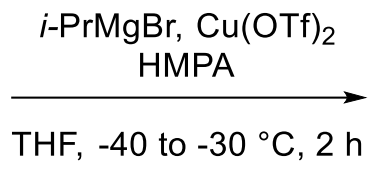

THF, -40 to $-30^{\circ} \mathrm{C}, 2 \mathrm{~h}$<smiles>CCOC(=O)C(CN[13F])=C(F)F</smiles>

121<smiles>CCOC[C@](C[Te]P)(N[Pb])C(F)(F)F</smiles>

122

Scheme 25. Reaction of aziridine $\mathbf{1 2 0}$ with a Grignard reagent.

Recently, Juncosa et al. reported the synthesis of (S)-3-amino-4-(difluoromethylenyl)cyclopent-1-ene-1carboxylic acid from its saturated analogue CPP-115 (Scheme 26, cf. Scheme 23). ${ }^{35}$ The first step included the protection of both amino and carboxylic group. Then, after using potassium hexamethyldisilazane and $\mathrm{PhSeCl}$, the phenylselenyl group was introduced to the $\alpha$-carbon. Next, deprotection of amino and carboxylic groups and elimination of PhSe-group furnished a mixture of the hydrochlorides of isomers 127 and 128 in a 5:3 ratio, respectively. One of the isomers, 128, turned out to be more reactive and was removed by a selective modification using a soft thiol nucleophile. Finally, the isomer $\mathbf{1 2 7}$ was isolated as a pure product. 


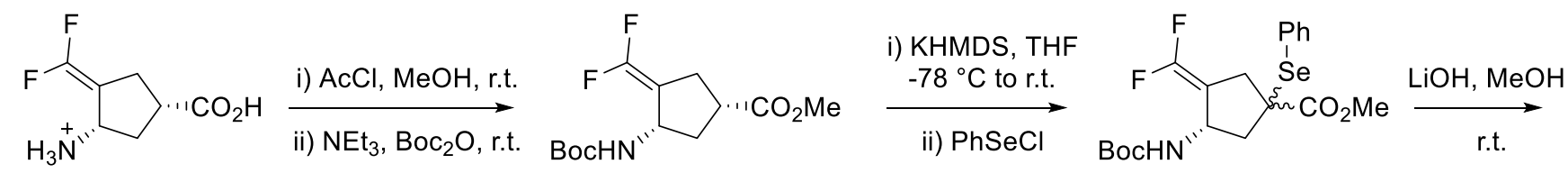

$\mathrm{Cl}^{-} 123$

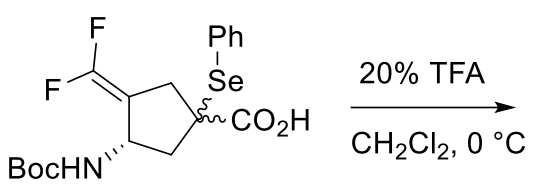

125
124

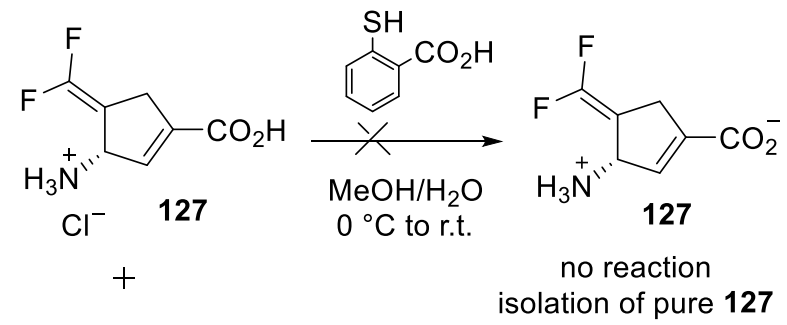<smiles>[NH3+][C@@H]1CC(C(=O)O)=CC1=C(F)F</smiles>

$\mathrm{Cl}^{-}$

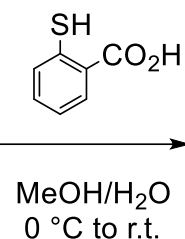

product removal

128

Scheme 26. Synthesis of (S)-3-Amino-4-(difluoromethylenyl)cyclopent-1-ene-1-carboxylic acid (127).

As shown before, in 1987 Kolb et al. ${ }^{17}$ described the synthesis of 4-amino-5,6,6-trifluoro-5-hexenoic acid (132) according to the procedure presented earlier (Scheme 21). In comparison to the synthesis of difluorinated derivative 109 they used 1,1,2-trifluoroethene in the second step and triethylamine in the final route (Scheme 27 ).

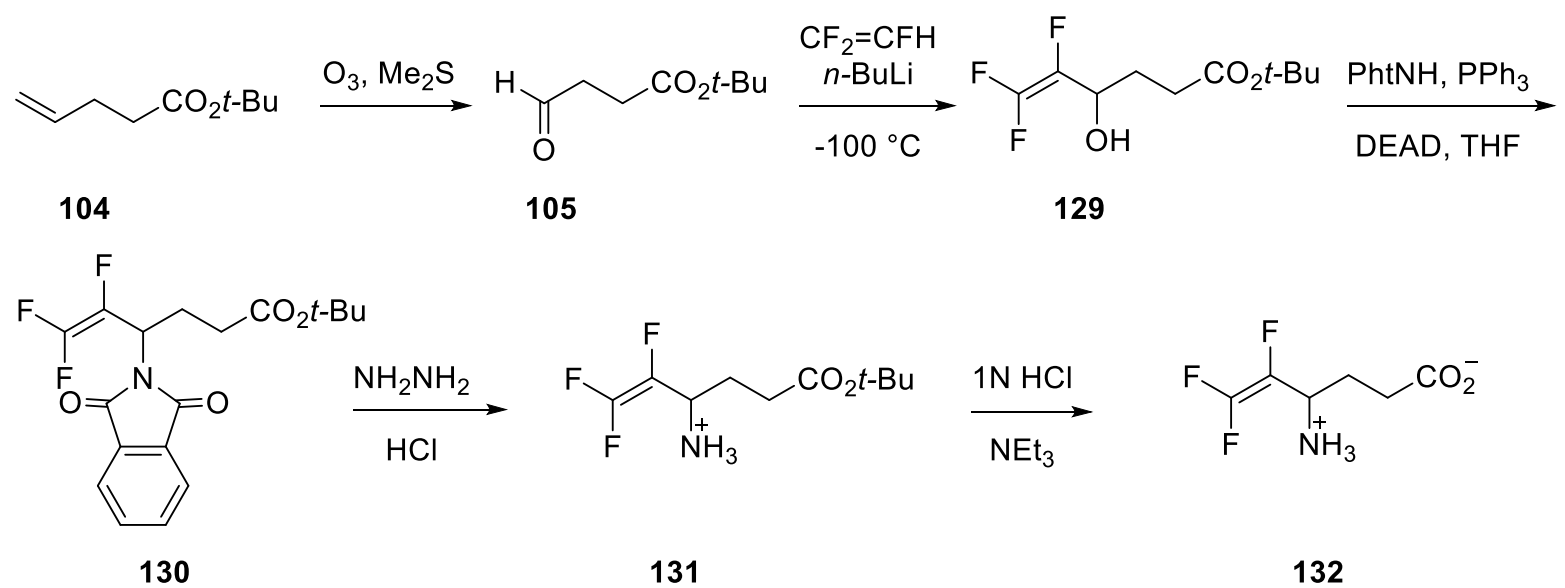

Scheme 27. Synthesis of 4-amino-5,6,6-trifluoro-5-hexenoic acid 132.

The preparation of trifluorovinyl amino acid 136 (Scheme 28) was presented by Castelhano et al. ${ }^{36}$ This route involved condensation of the Grignard reagent 133 with N-protected 2-chloroglycine methyl ester 134 and further acidic hydrolysis. 


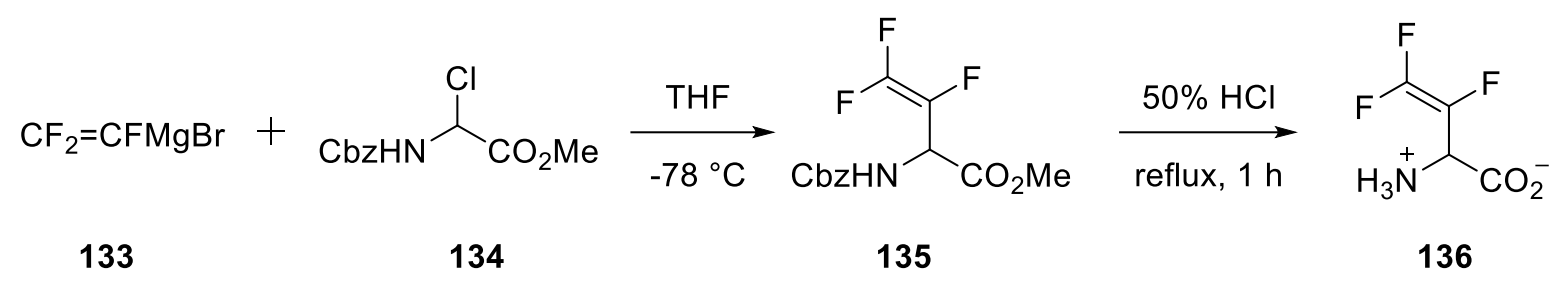

Scheme 28. Synthesis of trifluorovinyl amino acid 136.

\section{Conclusions}

The idea, that peptidomimetics, as analogues of natural peptides, can be useful alternative in therapy is well known. The expected differences in their biological activity are attributed to the "artificial" unit incorporated to the original peptide chain. Also, the fact, that fluorine introduced to organic molecules, can dramatically change their properties is generally known. Besides changes of physical properties such as hydrophilicity, lipophilicity, the reactivity and stability can also be influenced by the incorporation of fluorine(s) in a molecule. It affects bond energy, acidity and basicity, hydrogen bond formation and, what is very important - the geometry of the molecule. Among others, introducing fluorine substituted vinyl units into poly-amino acid chain are of special interest. The presence of fluorine(s) at vinylic moieties and their precise location can significantly impact their properties. This general idea, however, requires quite challenging synthetic methods to prepare such "imaginary beautiful" molecules. This short review presents recent synthetic approaches and achievements on synthesis of amino acid derivatives bearing fluorine-substituted olefinic motifs.

\section{Acknowledgements}

The work was supported by grant no. POWR.03.02.00-00-1020/17 co-financed by the European Union through the European Social Fund under the Operational Program Knowledge Education Development (KSK) as well as National Science Center grant no. UMO-2017/26/M/ST5/00437.

\section{List of Abbreviations}

2,2,6,6-TMP- 2,2,6,6-Tetramethylpiperidine

AIBN- Azobisisobutyronitrile

Boc- tert-Butyloxycarbonyl group

Cbz- Benzyloxycarbonyl group

DCC- $N, N^{\prime}$-Dicyclohexylcarbodiimide

DDQ- 2,3-Dichloro-5,6-dicyano-1,4-benzoquinone

DMAP- 4-Dimethylaminopyridine

DMF- Dimethylformamide

DMPU- $N, N^{\prime}$-Dimethylpropyleneurea

DMS- Dimethyl sulfide

DMSO- Dimethyl sulfoxide 
HMPT- Hexamethylphosphoramide

LDA- Lithium diisopropylamide

LiHMDS- Lithium bis(trimethylsilyl)amide

LiTMP- Lithium tetramethylpiperidide

NBS- $N$-Bromosuccinimide

PCC- Pyridinium chlorochromate

PMB- $p$-Methoxybenzyl group

(S)-Boc BMI- 2-tert-Butyl-3-methylimidazolidin-4-one

TEMPO- (2,2,6,6-Tetramethylpiperidin-1-yl)oxyl

TFA- Trifluoroacetic acid

TMSCl- Trimethylsilyl chloride

\section{References}

1. Choudhary, A.; Raines, R. T. Chem. Bio. Chem. 2011, 12, 1801-1807.

https://doi.org/10.1002/cbic.201100272

2. Dalvit, C.; Ko, S. Y.; Vulpetti, A. J. Fluorine Chem. 2013, 152, 129-135.

https://doi.org/10.1016/i.jfluchem.2013.01.017

3. Welch, J. T. Tetrahedron 1987, 43, 3123-3197.

https://doi.org/10.1016/S0040-4020(01)90286-8

4. Mann, J. Chem. Soc. Rev. 1987, 16, 381-436.

https://doi.org/10.1039/cs9871600381

5. O'Hagan, D. Chem. Soc. Rev. 2008, 37, 308-319.

https://doi.org/10.1039/B711844A

6. Smart, B. E. J. Fluorine Chem. 2001, 109, 3-11.

https://doi.org/10.1016/S0022-1139(01)00375-X

7. Hagmann, W. K. J. Med. Chem. 2008, 51, 4359-4369.

https://doi.org/10.1021/jm800219f

8. Wang, J.; Sánchez-Roselló, M.; Aceña, J. L.; del Pozo, C.; Sorochinsky, A. E.; Fustero, S.; Soloshonok, V. A.; Liu, H. Chem. Rev. 2014, 114, 2432-2506.

https://doi.org/10.1021/cr4002879

9. Moschner, J.; Stulberg, V.; Fernandes, R.; Huhmann, S.; Leppkes, J.; Koksch, B. Chem. Rev. 2019, 119, 10718-10801.

https://doi.org/10.1021/acs.chemrev.9b00024

10. Smits, R.; Cadicamo, C. D.; Burger, K.; Koksch, B. Chem. Soc. Rev. 2008, 37, 1727-1739.

https://doi.org/10.1039/b800310f

11. Interaction, P. F.; Does, O. W.; Affect, I. T.; Food, C. E. J. Am. Chem. Soc. 1984, 106, 3354-3356.

12. Michel, J.; Wagner, J.; Palfreymani, M. G. Bioorg. Chem. 1986, 118, 103-118.

13. Thornberry, N. A.; Bull, H. G.; Taub, D.; Greenlee, W. J.; Patchett, A. A.; Cordes, E. H. J. Am. Chem. Soc. 1987, 109, 7543-7544.

https://doi.org/10.1021/ja00258a056

14. Laćan, G.; Satyamurthy, N.; Barrio, J. R. Tetrahedron: Asymmetry 1995, 6, 525-536.

https://doi.org/10.1016/0957-4166(95)00036-O 
15. McDonald, I. A.; Palfreyman, M. G.; Jung, M.; Bey, P. Tetrahedron Lett. 1985, 26, 4091-4092. https://doi.org/10.1016/S0040-4039(00)89300-4

16. McDonald, I. A.; Bey, P. Tetrahedron Lett. 1985, 26, 3807-3810. https://doi.org/10.1016/S0040-4039(00)89256-4

17. Kolb, M.; Barth, J.; Heydt, J.; Jung, M. J. J. Med. Chem. 1987, 30, 267-272. https://doi.org/10.1021/jm00385a007

18. Silverman, R. B.; Bichler, K. A.; Leon, A. J. J. Am. Chem. Soc. 1996, 118, 1241-1252. https://doi.org/10.1021/ja9527885

19. McCarthy, J. R.; Huber, E. W.; Le, T.; Laskovics, F. M.; Matthewst, D. P. Tetrahedron 1996, 52, 45-58. https://doi.org/10.1016/0040-4020(95)00911-Q

20. Laue, K. W.; Mück-Lichtenfeld, C.; Haufe, G. Tetrahedron 1999, 55, 10413-10424. https://doi.org/10.1016/S0040-4020(99)00581-5

21. Wipf, P.; Henninger, T. C.; Geib, S. J. J. Org. Chem. 1998, 63, 6088-6089. https://doi.org/10.1021/jo981057v

22. Laue, K. W.; Kröger, S.; Wegelius, E.; Haufe, G. Eur. J. Org. Chem. 2000, 3737-3743. https://doi.org/10.1002/1099-0690(200011)2000:22<3737::AID-EJOC3737>3.0.CO;2-A

23. Berkowitz, D. B.; De La Salud-Bea, R.; Jahng, W. J. Org. Lett. 2004, 6, 1821-1824. https://doi.org/10.1021/ol049422u

24. Qiu, X. L.; Meng, W. D.; Qing, F. L. Tetrahedron 2004, 60, 5201-5206. https://doi.org/10.1016/j.tet.2004.04.044

25. Qiu, X. L.; Qing, F. L. J. Org. Chem. 2002, 67, 7162-7164. https://doi.org/10.1021/jo0257400

26. Qiu, X. L.; Qing, F. L. J. Org. Chem. 2003, 68, 3614-3617. https://doi.org/10.1021/jo034098m

27. Shendage, D. M.; Fröhlich, R.; Bergander, K.; Haufe, G. Eur. J. Org. Chem. 2005, 719-727. https://doi.org/10.1002/ejoc.200400665

28. Lübke, M.; Jung, M.; Haufe, G. J. Fluorine Chem. 2013, 152, 144-156. https://doi.org/10.1016/i.jfluchem.2013.03.011

29. Dunn, M. J.; Jackson, R. F. W.; Pietruszka, J.; Turner, D. J. Org. Chem. 1995, 60, 2210-2215. https://doi.org/10.1021/jo00112a048

30. Schilson, S. S.; Keul, P.; Shaikh, R. S.; Schäfers, M.; Levkau, B.; Haufe, G. Bioorg. Med. Chem. 2015, 23, 1011-1026. https://doi.org/10.1016/i.bmc.2015.01.014

31. McCune, C. D.; Beio, M. L.; Sturdivant, J. M.; De La Salud-Bea, R.; Darnell, B. M.; Berkowitz, D. B. J. Am. Chem. Soc. 2017, 139, 14077-14089. https://doi.org/10.1021/jacs.7b04690

32. Pan, Y.; Qiu, J.; Silverman, R. B. J. Med. Chem. 2003, 46, 5292-5293. https://doi.org/10.1021/jm034162s

33. Nadano, R.; Iwai, Y.; Mori, T.; Ichikawa, J. J. Org. Chem. 2006, 71, 8748-8754. https://doi.org/10.1021/jo061421n

34. Katagiri, T.; Katayama, Y.; Taeda, M.; Ohshima, T.; Iguchi, N.; Uneyama, K. J. Org. Chem. 2011, 76, 93059311.

https://doi.org/10.1021/jo201554g

35. Juncosa, J. I.; Takaya, K.; Le, H. V.; Moschitto, M. J.; Weerawarna, P. M.; Mascarenhas, R.; Liu, D.; Dewey, S. 
L.; Silverman, R. B. J. Am. Chem. Soc. 2018, 140, 2151-2164.

https://doi.org/10.1021/jacs.7b10965

36. Castelhano, A. L.; Horne, S.; Taylor, G. J.; Billedeau, R.; Krantz, A. Tetrahedron 1988, 44, 5451-5466.

https://doi.org/10.1016/S0040-4020(01)86051-8

\section{Authors' Biographies}

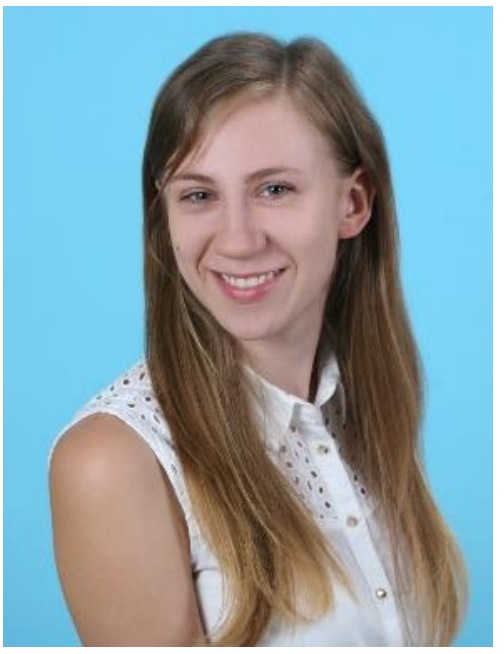

Katarzyna Salamon-Krokosz was born in 1994 in Poland. In years 2013-2016 she pursued a B.Sc. degree in general chemistry at Adam Mickiewicz University. In 2016, she undertook graduate studies in material chemistry and performed her Master's thesis focusing on the organometallic chemistry. Currently, she is working as a third-year Ph.D. student under the supervision of Prof. Henryk Koroniak. Her research focuses on the synthesis of monofluorovinyl amino acid derivatives with potential biological activity.

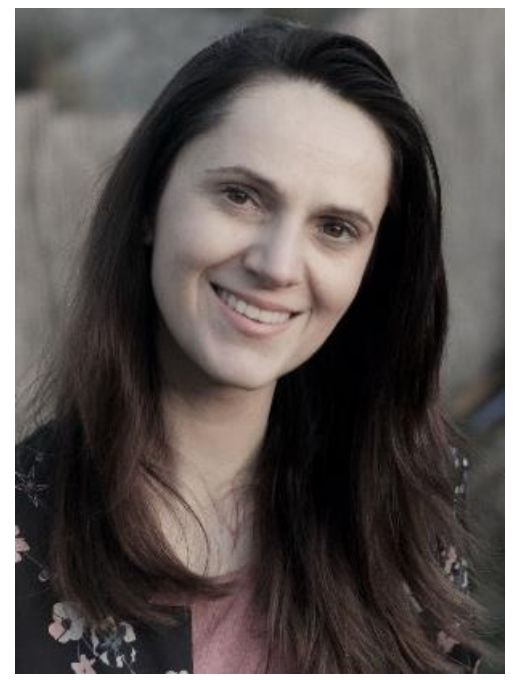

Katarzyna Koroniak-Szejn is currently working as an Assistant Professor at Adam Mickiewicz University in Poznań. She finished her studies and graduated the Master Thesis in 2005 at the Faculty of Chemistry of Adam Mickiewicz University in Poznań. Then, in 2008, she defended her PhD in Germany at the Westfälische Wilhelms-Universität w Münster under the supervision of Professor Günter Haufe. Next two years (2009 2011) she spent as post-doc at the Karlsruhe Institute of Technology in the group of Professor Stefan Bräse. 
After her return to the home University she continues the research work dealing mainly with the synthesis of fluorinated organic compounds with potential biological activity, derivatives of carbohydrates and amino acids.

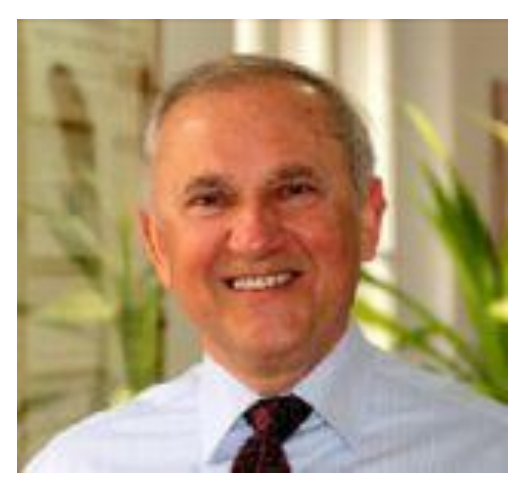

Henryk Koroniak is a Professor at Adam Mickiewicz University, Poznań, Poland. He is a Head of Department of Synthesis and Structure of Organic Compounds. His research activity includes: synthesis and structural studies of fluorine containing organic molecules, biologically active fluorochemicals, molecular modelling, and mostly fluorine influence on reactivity and structure of organic compounds. He serves presently as a Dean of Faculty of Chemistry, Adam Mickiewicz University. He was also involved in several activities related to his academic career such as Member of Polish State Committee for Scientific Research; Member of Editorial Board of Journal of Fluorine Chemistry; Editor of "On the borderline between chemistry and biology" (39 volumes up to 2019), Member of Council of The Foundation for Polish Science (FNP), Member of Fluorine Division, American Chemical Society. 